\title{
Arbutus Unedo Honey and Propolis Ameliorate Acute Kidney Injury, Acute Liver Injury, and Proteinuria via Hypoglycemic and Antioxidant Activity in Streptozotocin-Treated Rats
}

\author{
Soumaya Touzania Noori Al-Wailib Hamada Imtarac \\ Nawal Hammas ${ }^{d}$ Soraia Falcão ${ }^{e}$ Miguel Vilas-Boas ${ }^{e}$ \\ Abderrazak Aboulghazia \\ Wail Al-Wailib Badiaa Lyoussia \\ Ilham El Arabia
}

aLaboratory of Natural Substances, Pharmacology, Environment, Modeling, Health, and Quality of Life (SNAMOPEQ), Department of Biology, Faculty of Sciences Dhar Mehraz, Sidi Mohamed Ben Abdellah University, Fez, Morocco, 'b New York Medical Care for Nephrology, Richmond Hill, New York, NY, USA, 'Department of Biology and Biotechnology, Faculty of Arts and Sciences, Arab American University Palestine, Jenin, State of Palestine, dDepartment of Pathology, University Hospital Hassan II, Fez, Morocco, eCentro de Investigação de Montanha (CIMO), Instituto Politécnico de Bragança, Campus de Santa Apolónia, Bragança, Portugal

\section{Key Words}

Honey - Propolis - Proteinuria - Acute kidney injury • Liver injury - Hyperglycemia • Streptozotocin

\footnotetext{
Abstract

Background/Aims: Honey and propolis have biological and therapeutic effects in various pathological and clinical conditions such as hyperglycemia and diabetes. However, the combined use of honey and propolis has not been reported. The study evaluated the protective effect of Arbutus unedo honey, propolis and their combination in streptozotocin (STR)induced hyperglycemia, acute kidney injury (AKI), liver injury, dyslipidemia, and proteinuria in male Wistar rats. Methods: The study identified physicochemical characteristics, mineral and antioxidant content, and antioxidant activity in honey and propolis. Rats were assigned to five groups, with five rats in each group; control, STR-treated, STR-treated + honey $(1 \mathrm{~g} / \mathrm{kg} /$ day), STR-treated + propolis (100 mg/day), and STR-treated + honey and propolis. On day 15, blood glucose, insulin, HBA1c, kidney function tests, liver enzymes, lipid profile, hemoglobin, and urine protein, creatinine, glucose, and electrolytes were analyzed. Liver, pancreas, and kidney tissues were studied histologically. The mineral component in honey and propolis 


\section{Cellular Physiology Cell Physiol Biochem 2022;56:66-81

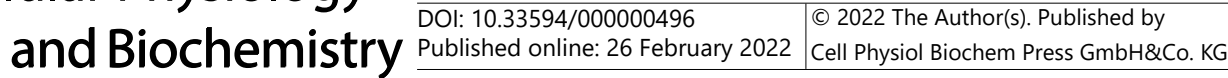 \\ Touzani et al.: Honey, Propolis, Acute Kidney Injury and Liver Injury}

was determined by atomic absorption spectrometry. Honey analysis was performed by HPLC. Chemical characterization of propolis was performed by LC/DAD/ESI-MS ${ }^{n}$. Measurement of blood and urine parameters was carried out with an automated analyzer (Architect c8000) and XT-1800i Automated Hematology Analyzer. Insulin concentration was determined by Elisa and insulin resistance was estimated by using HOMA-IR. Results: Honey and propolis contain a high quantity of antioxidants and exhibit in vitro antioxidant activity. In STR-treated rats, blood glucose, HBA1c, creatinine, blood urea, liver enzymes, and urine protein significantly increased compared to the control group $(P<0.05)$, while insulin, hemoglobin, and body weight significantly decreased. Histological changes were evident in the pancreas, kidney, and liver tissues. These results indicated AKI, liver injury, and pancreatic injury, which was evident with reducing the number of the island of Langerhans and marked hyperglycemia. The use of honey and propolis significantly $(P<0.05)$ attenuated liver and kidney injury, and proteinuria, and improved level of hemoglobin, HBA1c, and insulin toward the normal range. The combination of honey and propolis was more effective than honey or propolis individually $(P<0.05)$. Conclusion: the combination of propolis and honey can prevent STR-induced AKI, liver injury, proteinuria, dyslipidemia, anemia, hyperglycemia, and body weight loss, most likely by their hypoglycemic and antioxidant activities.

(C) 2022 The Author(s). Published by Cell Physiol Biochem Press GmbH\&Co. KG

\section{Introduction}

Hyperglycemia has a significant impact on the antioxidant system and carbohydrate, lipid, and protein metabolism. High blood glucose level (BGL) leads to oxidative stress, diabetic nephropathy, and renal failure, which natural antioxidants can be prevented [1]. Acute kidney injury (AKI), chronic kidney disease, and proteinuria are common in clinical practice and associated with significant comorbidity and mortality. There is no effective intervention for managing AKI and chronic kidney disease and preventing their progression to end-stage renal failure.

Honey is a bee product with marked biological and therapeutic properties. Honey has a favourable effect on diabetic nephropathy caused by streptozotocin (STR) [2]. Honey's hypoglycemic effect is most likely due to its content of antioxidants, zinc, copper, and selenium [3-5]. In STR-induced diabetic mice, honey prevents hyperglycemia, stimulates insulin secretion, ameliorates kidney and liver injury, and significantly enhances glucokinase activity [6]. Stingless bee honey prevents hyperglycemia, dyslipidemia, and histopathological changes in pancreatic islets of diabetic rats [7]. In normal individuals, honey has a beneficial outcome in kidney function and inflammatory mediators [8]. In lead and CCl4 intoxication, honey protects kidney and liver injuries and increases urine volume [9-11]. Furthermore, honey has diuretic, natriuretic and kaliuretic activity [12]. STR-induced diabetes in rats increases oxidative stress and decreases antioxidants in the kidneys, and honey attenuated these changes. Also, honey reduced mesangial matrix expansion and thickening of the glomerular basement membrane after diabetic induction [13].

The Holy books, The Talmud, the Old and New Testaments of The Bible, and The Holy Quran mentioned honey as a healer of diseases. In the Surat Al-Nahel (The Bee), it says: And the LORD (ALLAH) taught the bee to build its cells in the mountains, on the tree, and in men's habitation; then to eat of all the fruits of the earth, and find with skill the spacious paths of its LORD: there issues from within their bodies a drink of varying colors, wherein is healing for men, verily in this is a sign for those who give thought.

Propolis contains bioactive biochemical compounds, mainly phenols and flavonoids. Studies showed that propolis has antioxidant and hepato-renal protective activities $[12,14$, 15]. Propolis possesses higher antioxidant activity than honey [12]. Propolis is another bee product that improves BGL and increases insulin sensitivity in STR-induced diabetic rats [16, 17]. Studies showed that propolis significantly decreases BGL and oxidative stress in diabetic rats and explores anti-advanced glycation end-products activity $[18,19]$. In an earlier study, 


\section{Cellular Physiology Cell Physiol Biochem 2022;56:66-81 \\ and Biochemistry \begin{tabular}{l|l|l|l} 
DOl: 10.33594/000000496 & Published online: 26 February 2022 & 2022 The Author(s). Published by \\
Cell Physiol Biochem Press GmbH\&Co. KG
\end{tabular} \\ Touzani et al.: Honey, Propolis, Acute Kidney Injury and Liver Injury}

we found that propolis can decrease urinary protein excretion and prevent liver and kidney function deterioration caused by ethylene glycol ingestion in rats [20].

The composition of propolis and honey varies qualitatively and quantitatively; it depends on the botanical origins, the geographical areas, the bee species, and the season of collection $[21,22]$. Studies showed that propolis and honey collected from different regions have an important impact on BGL in diabetic animals. However, the effect on glucose homeostasis, kidney and liver functions, and lipids might not be the same among different samples. Therefore, the combination of honey and propolis might have an additive or synergistic effect.

STR is commonly used to induce hyperglycemia and diabetes type 1 in rats. It was found that STR induces in vivo DNA strand breaks and NAD depletion in the islets of Langerhans, which is prevented by radical's scavengers [23, 24]. STR causes the generation of free radicals resulting in DNA strand breaks [24]. In addition, STR induces insulitis and type 1 diabetes in rats [25]. Therefore, STR causes a diabetic state by its inflammatory and oxidant activity. Others and we have found that propolis and honey have anti-inflammatory and antioxidant activity, and accordingly, they represent a great candidate to be used to prevent or even treat diabetes and its complications. STR causes hyperglycemia, pancreatic damage, AKI, and liver injury. Therefore, the use of honey, propolis, and their combination to prevent renal, hepatic, and pancreatic function deterioration are reasonable.

The present study evaluated honey and propolis's effect, collected from Moroccan areas, on BGL, insulin level, HBA1c, body weight, kidney and liver function, proteinuria, and lipids 15 days after induction of type 1 diabetes in rats. Furthermore, physicochemical characteristics, antioxidant content, and antioxidant activity of propolis and honey samples were studied. STR was used to induce type 1 diabetes in the Wistar rat model. Many studies have used Wistar rats to induce hyperglycemia and diabetes state by STR [26, 27]. Therefore, the animal model's selection and the experiment's protocol are used widely to induce type 1 diabetes [28]. The acute effect of STR administration and hyperglycemia is studied within days after administration of STR. However, diabetic complications were observed several weeks after administration of STR. Therefore, our data showed an acute effect of STR and hyperglycemia in rats.

\section{Materials and Methods}

\section{Collection and extraction of propolis}

The investigators obtained propolis from colonies of honeybees in the Sefrou province (Morocco). The collected propolis was frozen at $-20^{\circ} \mathrm{C}$ and ground in a chilled mortar. The ground powder (30 grams) was extracted using $100 \mathrm{~mL}$ of ethanol 70\% at ambient temperature and maceration under agitation for one week. The solution was filtered through a Whatman filter paper and concentrated in a rotary evaporator under reduced pressure to get a solid residue. The residue was dissolved in a minimal volume of ethanol and stored at $-20^{\circ} \mathrm{C}$ until use. During the experiment, distilled water was added to obtain the required propolis concentrations.

\section{Honey samples}

Arbutus unedo honey was purchased from beekeepers, Fez, boulemane, Morocco. The honey sample was collected from chefchaouen region.

\section{The physicochemical content of honey}

The study followed the International Honey Commission (IHC) standardized methods to assess the free acidity, $\mathrm{pH}$, moisture, electrical conductivity, and ash [29]. The color was determined with a spectrophotometer by reading the absorbance of honey aqueous solutions at $635 \mathrm{~nm}(50 \% \mathrm{~W} / \mathrm{V})$ [30]. Melanoidin's content was estimated based on the browning index (net absorbance at A450-A720) [31], and the results were expressed as absorption units. The experiment was conducted in triplicate. 


\section{$\begin{array}{lll}\text { Cellular Physiology } & \text { Cell Physiol Biochem 2022;56:66-81 } \\ \text { DOl: 10.33594/000000496 } & \text { O 2022 The Author(s). Published by } \\ \text { and Biochemistry Published online: 26 February 2022 } & \text { Cell Physiol Biochem Press GmbH\&Co. KG }\end{array}$ \begin{tabular}{ll|l} 
and Biochemistry & $\begin{array}{l}\text { DOI: 10.33594/000000496 } \\
\text { Published online: } 26 \text { February } 2022\end{array}$ & $\begin{array}{l}\text { C } 2022 \text { The Author(s). Published by } \\
\text { Cell Physiol Biochem Press GmbH\&Co. KG }\end{array}$ \\
\cline { 2 - 4 } Touzani et al.: Honey, Propolis, Acute Kidney Injury and Liver Injury &
\end{tabular}}

Mineral analysis in honey and propolis

The mineral component in honey and propolis samples was determined by atomic absorption spectrometry [32].

\section{Total phenolic content in honey}

The total phenolic content in the honey sample was determined using Folin-Ciocalteu's phenol reagent $(0.2 \mathrm{~N})$ and $\left.7.5 \% \mathrm{Na}_{2} \mathrm{CO}_{3}\right)$ [33]. The experiment was conducted in triplicate, and total polyphenol content was expressed as milligrams of gallic acid equivalents per 100 gram of honey sample used for constructing the calibration curve.

\section{Determination of total flavonoid content}

The evaluation of flavonoid content was carried out as previously described by a colorimetric method with the use of $\mathrm{AlCl}_{3}$ ethanol solution (2\%) and $\mathrm{NaNO}_{2}$ (4\%) [34]. The experiment was conducted in triplicate, and total flavonoid content was calculated using a quercetin solution's standard calibration.

\section{Flavones and flavonol content}

The flavone and flavonol content was determined with the use of $\mathrm{AlCl}_{3}$ [34]. The content was calculated as mg quercetin equivalents per $\mathrm{mL}\left(\mathrm{mg} \mathrm{QE} \mathrm{mL}^{-1}\right)$ using a calibration curve. The experiment was conducted in triplicate.

\section{Honey analysis by HPLC}

The honey sample was subjected to base hydrolysis and extracted with ethyl acetate (liquid-liquid extraction) [35]. Pure external standards were used, including syringic acid, tannic acid, caffeic acid, ferulic acid, coumaric acid, gallic acid, rosmarinic acid, epicatechin pyrogallol. Phenolic compounds of honey extracts were identified by comparing their retention times with those of the standards. The results were obtained in $\mathrm{mg} / 100$ gram of honey.

\section{Determination of total antioxidant activity}

The total antioxidant activity was estimated by the phosphomolybdenum method according to Prieto, Pineda, \& Aguilar, 1999 [36]. The experiment was conducted in triplicate, and values are expressed as equivalents of ascorbic acid in mg per gram of propolis.

\section{Free radical scavenging activity (DPPH)}

Scavenging of the 2,2-diphenyl-1- picrylhydrazyl (DPPH) radical was assayed following the method of Miguel et al. [37]. The percentage inhibition [(A0-A1/A0)*100] was plotted against phenol content, and $\mathrm{IC}_{50}$ was determined (concentration of total phenol able to scavenger $50 \%$ of DPPH free radical). Butylated hydroxytoluene (BHT) was used as a positive control. The experiment was conducted in triplicate

\section{Reducing Power}

The reducing power was determined according to the method described by Oyaizu, 1986 [38]. The absorbance of the mixture was measured at $700 \mathrm{~nm}$. Ascorbic acid was used as a positive control. The experiment was conducted in triplicate.

\section{Chemical characterization of propolis by LC/DAD/ESI-MS ${ }^{n}$}

The liquid chromatography, with diode array detection and electrospray ionization mass spectrometry (LC-DAD-ESI/MS) analyses, was performed on a Dionex Ultimate 3000 UPLC instrument (Thermo Scientific, San Jose, CA, USA) equipped with a diode-array detector. The HPLC was run on a Macherey-Nagel Nucleosil C18 column (250 $\mathrm{mm} \times 4 \mathrm{~mm}$ id; $5 \mathrm{~mm}$ particle diameter, end-capped), and its temperature was maintained at $30{ }^{\circ} \mathrm{C}$. The LC conditions used were according to Falcão et al. [39]. The mass spectrometer was operated in the negative ion mode using a Linear Ion Trap LTQ XL mass spectrometer (Thermo Scientific, San Jose, CA, USA) equipped with an ESI source. Control and data acquisition was carried out with the Xcalibur $®$ data system (Thermo Scientific, San Jose, CA, USA). 


\section{Cellular Physiology Cell Physiol Biochem 2022;56:66-81

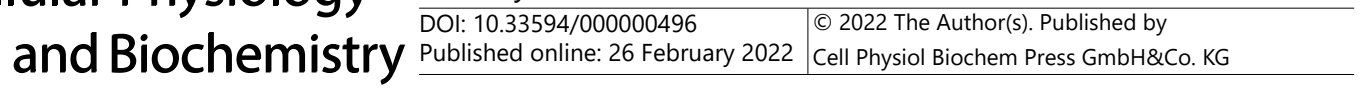 \\ Touzani et al.: Honey, Propolis, Acute Kidney Injury and Liver Injury}

Quantification was achieved using calibration curves [40]. Concentrations of all compounds in propolis samples were calculated based on the peak area ratio. The following calibration curves were used: for caffeic acid $\left(0.002-0.35 \mathrm{mg} / \mathrm{mL} ; \mathrm{y}=3 \times 10^{7} \mathrm{x}-78726 ; \mathrm{R}^{2}=0.999\right)$, p-coumaric acid $(0.02-0.15 \mathrm{mg} / \mathrm{mL}$; $\left.\mathrm{y}=5 \mathrm{x} 10^{7} \mathrm{x}-94095 ; \mathrm{R}^{2}=0.999\right)$, chrysin $\left(0.0025-0.16 \mathrm{mg} / \mathrm{mL} ; \mathrm{y}=2 \mathrm{x} 10^{7} \mathrm{x}-7021 ; \mathrm{R}^{2}=0.999\right)$, kaempferol $\left(0.005-0.075 \mathrm{mg} / \mathrm{mL} ; \mathrm{y}=6 \times 10^{6} \mathrm{x}-2761 ; \mathrm{R}^{2}=0.999\right)$ and pinocembrin $\left(0.005-1 \mathrm{mg} / \mathrm{mL} ; \mathrm{y}=2 \times 10^{7} \mathrm{x}-247019\right.$; $\left.\mathrm{R}^{2}=0.999\right)$. When the standard was not available, the compound quantification was expressed in equivalent of the structurally closest compound. The assay was performed in triplicate and the results were expressed as $\mathrm{mg} / \mathrm{gram}$ of extract.

\section{Experimental animals}

Adult male Wistar rats weighing $178 \pm 21$ grams were obtained from the animal house breeding centre, Faculty of Sciences, Dhar Al-Mahraz Fez, and were housed under normal environmental conditions $\left(25 \pm 1{ }^{\circ} \mathrm{C}, 55 \pm 5 \%\right.$ humidity and $12 \mathrm{~h} / 12 \mathrm{~h}$ cycle light/dark).

\section{Experimental design}

Twenty-five male Wistar rats were randomly divided into five groups; each contains five rats.

Group I (control): the animals received distilled water $(10 \mathrm{ml} / \mathrm{kg} /$ day).

Group II (STR-treated): the animals received STR and were treated with distilled water $(10 \mathrm{ml} / \mathrm{kg} / \mathrm{day})$.

Group III (STR-treated + honey): the animals received STR and were treated with honey in $10 \mathrm{ml}$ distilled water $(1 \mathrm{~g} / \mathrm{kg} /$ day).

Group IV (STR-treated + propolis): the animals received STR and were treated with propolis in $10 \mathrm{ml}$ distilled water $(100 \mathrm{mg} / \mathrm{kg} /$ day).

Group V (STR-treated + propolis and honey): the animals received STR and were treated daily by a mixture containing honey $(1 \mathrm{~g} / \mathrm{kg})$ and propolis $(100 \mathrm{mg} / \mathrm{kg})$ in $10 \mathrm{ml}$ distilled water.

STR-treated rats recieved an intravenous injection of $60 \mathrm{mg}$ STR (Sigma-Aldrich Inc., USA) per kilogram of body weight dissolved in a citrate buffer $(0.1 \mathrm{M}, \mathrm{pH} 4.5)$. After 48 hours, hyperglycemia was confirmed using a Glucometer (Accu-chek active). Animals with fasting BGL greater than $200 \mathrm{mg} / \mathrm{l}$ were included in the study.

The animals were treated with the interventions for 14 days by gavage. The blood and urine samples and kidney, liver, and pancreatic tissues were collected from each rat on day 15 after induction of type 1 diabetes. To investigate the protective effect of the interventions in STR-induced reno-hepatic injury and hyperglycemia, the investigators started to administer the interventions two days after injection of STR (when hyperglycemia was evident).

\section{Blood and urine analysis}

On day 15, after starting treatment with the interventions, blood samples were collected from the anesthetized animals in all groups by the retro-orbital puncture using capillary tubes. The blood was analyzed for the BGL, triglycerides (TG), total cholesterol (TC), high-density lipoprotein (HDL) cholesterol, creatinine, blood urea (BU), and protein level. Hepatic function was evaluated by measuring serum alkaline phosphatase (PAL), alanine aminotransferase (ALT), aspartate aminotransferase (AST), and Lactate Dehydrogenase (LDH). Creatinine kinase was measured. The determination of the studied parameters' values was carried out with an automated analyzer (Architect c8000).

Insulin concentration was determined by Elisa using anti-human insulin antibodies (Diagnostic Systems). Insulin resistance (IR) was estimated by using the homeostasis model index of IR (HOMA-IR [41]. Hematological parameters (hematocrit, hemoglobin, platelet (PLC), white blood count) were determined with XT-1800i Automated Hematology Analyzer by sysmex.

On day 14, the rats were placed in metabolic cages, and urine was collected for 24 hours. Then, the determination of the values of the studied variables in the urine was carried out with an automated analyzer (Architect c8000).

\section{Histopathological study}

The histopathological study was conducted at Pathology Laboratory, University Hospital of Fez. At the end of the experiment, rats were euthanized with ketamine. Each rat's right kidney, liver, and pancreas in all groups were resected, put into $10 \%$ formalin, and embedded in paraffin. Sections of (5-6 $\mathrm{mm})$ were prepared 


\section{Cellular Physiology Cell Physiol Biochem 2022;56:66-81 \\ \begin{tabular}{ll|l} 
and Biochemistry & $\begin{array}{l}\text { DOl: 10.33594/000000496 } \\
\text { Published online: 26 February 2022 }\end{array}$ & $\begin{array}{l}\text { 2022 The Author(s). Published by } \\
\text { Cell Physiol Biochem Press GmbH\&Co. KG }\end{array}$ \\
\cline { 2 - 3 }
\end{tabular} \\ Touzani et al.: Honey, Propolis, Acute Kidney Injury and Liver Injury}

using a rotating microtome and deparaffined with xylene. The sections were stained with hematoxylin and eosin staining and observed under a light microscope (magnifications of 400x).

Statistical analysis

The values were expressed as the mean \pm SD. All statistical comparisons between the groups were performed by Student t-test and one-way analysis of variance (ANOVA), followed by post hoc "Tukey's Multiple Comparison Test" using Graphpad Prism 5 software.

\section{Results}

The physicochemical characterization of honey

The physicochemical characterization of Arbutus unedo honey showed pH; $4.19 \pm 0.01$, free acidity $(\mathrm{mEq} / \mathrm{kg}) ; 30.83 \pm 1.44$, electrical conductivity $(\mu \mathrm{S} / \mathrm{cm}) ; 686 \pm 5.03$, moisture; $(20 \pm 0.02 \%)$, ash (\%); $0.37 \pm 0.001$, color (A560-A720), melanoidin (A450-A720); $0.99 \pm$ 0.02 , pfund scale; $96.88 \pm 5.49$, and honey color; amber.

\section{Mineral and phenolic content of honey and propolis}

Arbutus unedo honey contains calcium $294.5 \mathrm{mg} / \mathrm{kg}$, potassium $2258 \mathrm{mg} / \mathrm{kg}$, magnesium $38 \mathrm{mg} / \mathrm{kg}$, and sodium $175 \mathrm{mg} / \mathrm{kg}$. Propolis contains a higher amount of calcium; 1220 $\mathrm{mg} / \mathrm{kg}$, magnesium; $598 \mathrm{mg} / \mathrm{kg}$ and sodium; $650 \mathrm{mg} / \mathrm{kg}$, and less potassium; $487 \mathrm{mg} / \mathrm{kg}$ compared to honey.

Propolis contains a significantly higher content $(P<0.05, \mathrm{P}=0.0001)$ of phenols $(135.15 \pm$ $1.42 \mathrm{mgGAE} / 100 \mathrm{~g}$ ), flavonoids $(130.19 \pm 0.41 \mathrm{mg} \mathrm{QE} / 100 \mathrm{~g})$, and flavonols $(108.11 \pm 0.51$ $\mathrm{mg} \mathrm{QE} / 100 \mathrm{~g})$ and higher antioxidant activity towards DPPH $\left(0.02 \pm 0.03 \mathrm{IC}_{50}=\mathrm{mg} / \mathrm{ml}\right)$ and FRAP $\left(0.041 \pm 0.02 \mathrm{IC}_{50}=\mathrm{mg} / \mathrm{ml}\right.$ ) than honey (phenols; $73.20 \pm 2.74 \mathrm{mgGAE} / 100 \mathrm{~g}$, flavonoids; $44.47 \pm 1.80 \mathrm{mg}$ QE/100 g, flavonols; $15.91 \pm 0.10 \mathrm{QE} / 100 \mathrm{~g}, \mathrm{DPPH} ; 5.89 \pm 0.06$ $\mathrm{IC}_{50}=\mathrm{mg} / \mathrm{ml}$, and FRAP; $3.44 \pm 0.24 \mathrm{IC}_{50}=\mathrm{mg} / \mathrm{ml}$ ).

With the use of HPLC, the analysis of phenolic compounds in the honey sample showed that the content (mg/100-gram honey) includes syringic acid $0.93 \pm 0.06$, tannic acid $3.66 \pm$ 0.18 , ferulic acid $2.16 \pm 0.13$, coumaric acid $1.85 \pm 0.06$, gallic acid $5.34 \pm 1.47$, epicatechin $4.76 \pm 0.48$, and pyrogallol $8.34 \pm 3.13$. No caffeic acid and rosmoric acid were detected (Fig. 1).

Phenols, total flavonoids, Flavone \& flavonol content of propolis

The LC/DAD/ESI-MSn analysis of the phenolic compounds in the Moroccan propolis sample identified 18 compounds, shown in Fig. 2 and Table 1. The compounds detected were phenolic acids and their ester derivatives, di-hydroflavanones and their ester derivatives, flavones and their methylated derivatives, flavonols and methylated derivatives, and flavanone. Among the identified compounds, pinobanksin-3-0-acetate, pinocembrin, and caffeic acid phenylethyl ester were the most abundant phenolics found in the sample. In phenolic classes, di-hydroflavanones such as pinobanksin and their ester derivatives were present in the highest quantity, followed by phenolic acids, such as caffeic acid, and their ester derivatives.

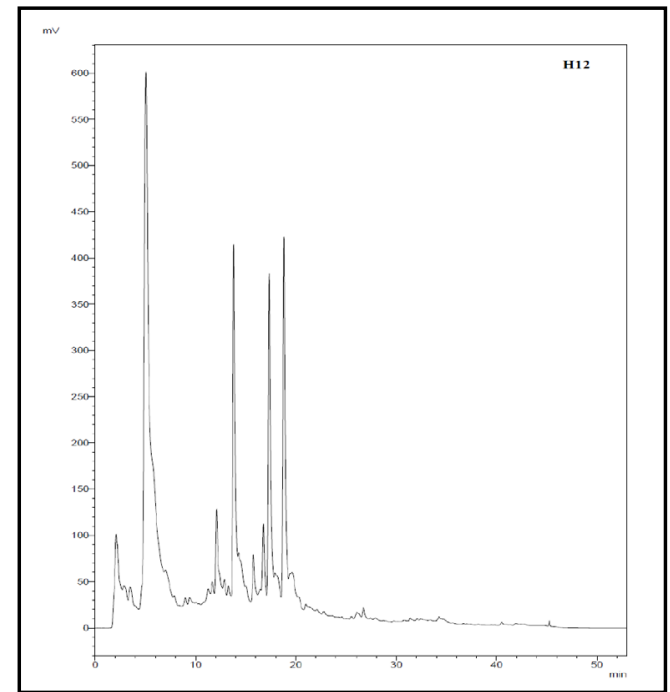

Fig. 1. HPLC chromatogram of Arbutus honey phenolics, detection at $280 \mathrm{~nm}$. 
Fig. 2. Chromatographic profile of the sample MG1 obtained at $280 \mathrm{~nm}$ for phenolic propolis extract by LC/DAD/ ESI-MS ${ }^{\text {n. }}$

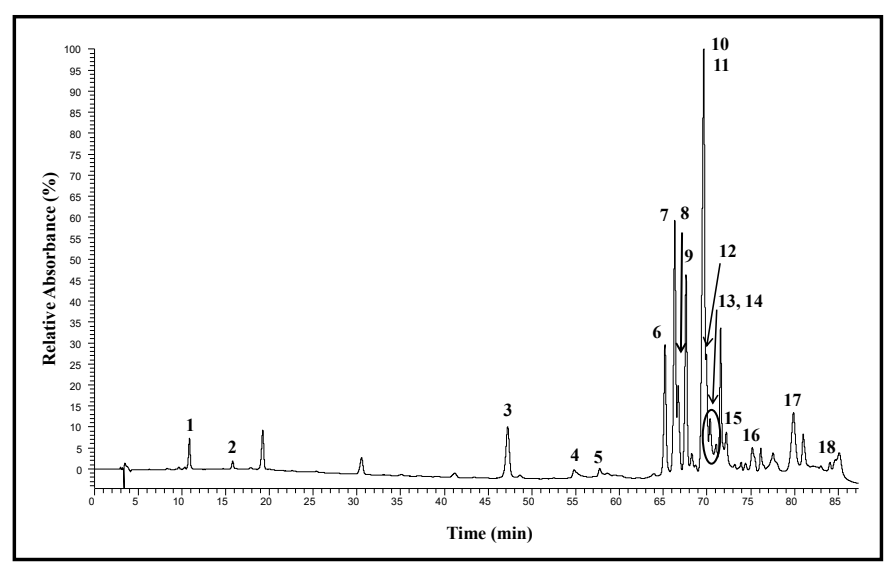

Table 1. Identification and quantification of phenolic compounds from Morocco propolis by LC/DAD/ESI$\mathrm{MS}^{\mathrm{n}}$. ${ }^{\mathrm{a}}$ Confirmed with the standard; ${ }^{\mathrm{b}}$ Confirmed with MS ${ }^{\mathrm{n}}$ fragmentation; ${ }^{\mathrm{c} C o n f i r m e d}$ with Falcão et al. [39]

\begin{tabular}{|c|c|c|c|c|c|}
\hline Compound & $\begin{array}{l}\mathrm{RT} \\
(\mathrm{min})\end{array}$ & $\begin{array}{r}\lambda_{\max } \\
(\mathrm{nm})\end{array}$ & {$[\mathrm{M}-\mathrm{H}] \cdot \mathrm{m} / \mathrm{z}$} & $\begin{array}{c}\text { MS }^{2} \\
\text { (\% base peak) }\end{array}$ & $\begin{array}{c}\mathrm{mg} / \text { gram } \\
\text { extract }\end{array}$ \\
\hline Caffeic acida, (1) & 10.9 & 322 & 179 & 135 & $0.50 \pm 0.00$ \\
\hline p-Coumaric acida,b (2) & 15.8 & 310 & 163 & 119 & $0.21 \pm 0.00$ \\
\hline Pinobanksin' ${ }^{\mathrm{b}, \mathrm{c}}(3)$ & 47.2 & 292 & 271 & $253(100), 225$ (26), $151(10)$ & $2.04 \pm 0.00$ \\
\hline Apigenina, ${ }^{a, b}(4)$ & 54.9 & 268,337 & 269 & 225 (100), 151 (29) & $0.27 \pm 0.00$ \\
\hline Kaempferol-methyl etherb,c (5) & 57.7 & 265,352 & 299 & 284 & $0.43 \pm 0.02$ \\
\hline Caffeic acid isoprenyl estera,b (6) & 65.2 & 325 & 247 & 179 (100), 135 (13) & $1.73 \pm 0.01$ \\
\hline Caffeic acid isoprenyl ester b,c (7) & 66.3 & 325 & 247 & $179(100), 135$ (13) & $3.00 \pm 0.01$ \\
\hline Caffeic acid benzyl esterb,c (8) & 66.7 & 325 & 269 & $178(100), 161(12), 134(32)$ & $1.18 \pm 0.03$ \\
\hline Pinocembrin ${ }^{a, b}(9)$ & 67.6 & 289 & 255 & 213 (100), 211 (32), 151 (48) & $3.91 \pm 0.15$ \\
\hline Chrysin $^{a, b}(10)$ & 69.6 & 268,313 & 253 & 225 (17), $209(100), 151(5)$ & $1.99 \pm 0.14$ \\
\hline Pinobanksin-3-0-acetateb,c (11) & 69.6 & 292 & 313 & $271(20), 253(100)$ & $6.82 \pm 0.06$ \\
\hline Caffeic acid phenylethyl ester ${ }^{\mathrm{a}, \mathrm{b}}(12)$ & 69.9 & 325 & 283 & $179(100), 135(22)$ & $1.24 \pm 0.03$ \\
\hline Galangin $^{a, b}(13)$ & 70.3 & 265,300 sh, 358 & 269 & $\begin{array}{c}269(100), 241(61), 227(20), \\
197(22), 151(20)\end{array}$ & $3.42 \pm 0.08$ \\
\hline Caffeic acid pentyl esterb (14) & 71.1 & 325 & 249 & 179 (100), $161(47), 135$ (32) & $0.62 \pm 0.00$ \\
\hline 6-Methoxychrysin ${ }^{\mathrm{b}, \mathrm{c}}(15)$ & 72.3 & $265,300 \mathrm{sh}, 350 \mathrm{sh}$ & 283 & 269 & $0.88 \pm 0.05$ \\
\hline Pinobanksin-3-0-propionate ${ }^{b, c}(16)$ & 75.2 & 289 & 327 & $271(9), 253(100)$ & $1.08 \pm 0.01$ \\
\hline Pinobanksin-3-0-butyrate or isobutyrate ${ }^{b, c}(17)$ & 79.9 & 292 & 341 & $271(2), 253(100)$ & $2.66 \pm 0.01$ \\
\hline Pinobanksin-3-0-pentanoate or 2-methylbutyrate ${ }^{b, c}(18)$ & 84.1 & 292 & 355 & $271(3), 253(100)$ & $0.80 \pm 0.00$ \\
\hline
\end{tabular}

Effect of the interventions on blood glucose level and insulin

The use of honey or propolis caused a significant lowering of BGL in the STRtreated group compared to the honey or popolis untreated STRtreated group; honey was more effective than propolis $(P<0.05)$ (Table 2). The combination of honey and propolis treatment causes a significant lowering of BGL compared to the STR-treated group; the combination was more effective than honey and propolis individually.

On day 15, there was a significant lowering in insulin level in STR treated rats (Table 3). The use of honey, propolis, and their combination significantly elevated insulin levels; the combination was more effective than honey or propolis individually $(P<0.05)$. In STR treated rats, there was a significant increase in HOMA-IR and a decrease in QUIKI $\left({ }^{*} 10-2\right)(p<0.05)$. Using honey, propolis, or their combination cause similar findings. 
Table 3. Effect of STR, honey, and propolis on the renal function test and plasma electrolytes and insulin on day 15. STR; Streptozotocin. * $\mathrm{P}<0.05$; compared to control. $+\mathrm{P}<0.05$; compared to STR. \& $<<0.05$; compared to STR+ honey. $\times \mathrm{P}<0.05$; compared to STR+ propolis

\begin{tabular}{|c|c|c|c|c|c|c|}
\hline Variables & Control & STR & Honey+ STR & Propolis + STR & Honey+propolis + STR & $\mathrm{F} / \mathrm{P}$ values \\
\hline Creatinine (mg/dl) & $0.4 \pm 0.02$ & $0.53 \pm 0.02^{*}$ & $0.43 \pm 0.04+$ & $0.49 \pm 0.05^{*}$ & $0.41 \pm 0.01+x$ & $0.077 / 0.988$ \\
\hline Blood urea (mg/dl) & $22 \pm 3$ & $47 \pm 6.8^{*}$ & $26 \pm 7+$ & $45 \pm 12^{*}$ & $25 \pm 1+x$ & $15.0 / 0.000$ \\
\hline Uric acid (mgd/l) & $0.95 \pm 0.05$ & $0.96 \pm 0.04$ & $0.92 \pm 0.04$ & $0.97 \pm 0.04$ & $0.92 \pm 0.01$ & $1.790 / 0.17$ \\
\hline Total protein (g/dl) & $5.8 \pm 0.15$ & $5.73 \pm 0.17$ & $6.20 \pm 0.22^{*}$ & $6.55 \pm 0.17 *_{+}$ & $5.86 \pm 0.11 x$ & $35.03 / 0.000$ \\
\hline Potassium (mmol/l) & $4.36 \pm 0.46$ & $3.8 \pm 0.25$ & $4.67 \pm 0.08+$ & $3.7 \pm 0.45 \&$ & $4.14 \pm 0.09+$ & $8.123 / 0.0005$ \\
\hline Sodium (mmol/l) & $141 \pm 2.69$ & $137 \pm 6.80$ & $137 \pm 2.00$ & $151 \pm 8.54+\&$ & $139 \pm 8.48$ & $6.638 / 0.0014$ \\
\hline Chloride (mmol/l) & $100 \pm 3.35$ & $93 \pm 3.26$ & $94 \pm 5.10$ & $107 \pm 9.12+$ & $99 \pm 1.14$ & $6.005 / 0.002$ \\
\hline Insulin (ng/ml) & $1.40 \pm 0.12$ & $0.47 \pm 0.02 *$ & $1.66 \pm 0.16^{*}+$ & $1.63 \pm 0.14^{*}+$ & $1.98 \pm 0.18^{*}+\& \mathrm{x}$ & $89.14 / 0.000$ \\
\hline HOMA-IR & $11.04 \pm 0.11$ & $13.68 \pm 0.24 *$ & $29.84 \pm 0.10^{*}+$ & $43.14 \pm 0.09 * \&+$ & $20.54 \pm 0.85+\& x$ & $5122 / 0.000$ \\
\hline QUICKI (*10-2) & $41.74 \pm 0.4$ & $40.18 \pm 0.4^{*}$ & $35.37 \pm 0.6^{*}+$ & $33.47 \pm 0.4^{*}+\&$ & $35.52 \pm 0.6^{*}+x$ & $254.93 / 0.000$ \\
\hline
\end{tabular}

Effect of the interventions on HBA1c

There was a significant elevation of HBA1c on day 15 in the STR-treated group compared to the control $(11 \pm 0.08 \mathrm{vZ}$ $15.5 \pm 0.89, P<0.05)$. The treatment with honey (HBA1c:14.4 \pm 0.63 ) or honey and propolis combined (HBA1c:12.5 \pm 0.44 ) caused a considerable lowering of HBA1c in STR treated group $(P<0.05)$. There is no significant difference between STR-treated and STR-treated + propolis groups (15.5 \pm $0.89 \mathrm{vz} 15.2 \pm 0.39, P>0.05)$. STR caused a significant decrease in the body weight on day 15 after the induction of hyperglycemia, which was significantly alleviated with the use of honey alone or honey with propolis (Fig. 3).

\section{Effect of the intervention of kidney function and blood electrolytes}

There was a significant elevation of creatinine and BU in the STR-treated group compared to the control group on day 15 (Table 3). The use of honey or a combination of honey and propolis significantly alleviated the increase in creatinine and BU levels $(P<0.05)$. There was no significant change in serum electrolytes level.

\section{Effects of the interventions on urine protein and electrolytes}

In STR-treated rats, there was a significant elevation $(P<0.05)$ of urine glucose, protein, and albumin, and a substantial decrease in the urinary excretion of creatinine, urea, uric acid, phosphorous, and magnesium (Table 4). The administration of honey, propolis, and their combination significantly alleviated these changes $(P<0.05)$. The combination of honey and propolis was more effective than honey or propolis individually. There was no significant change in the urine electrolytes.

\section{Effect of the intervention on liver enzymes, lipids, and hemoglobin}

In STR-treated rats, there was a significant elevation in the liver enzymes, cholesterol, TG, LDH, and lowering in HDL and hemoglobin level $(P<0.05)$ (Table 5). The use of honey, propolis, or their combination caused a significant decrease of elevated liver enzymes, lipids, and LDH towards average level $(P<0.05)$. Also, the interventions caused a considerable increase in hemoglobin, hematocrit, and HDL level compared to the STR-treated group. The combination of propolis and honey was more effective than honey or propolis individually $(P<0.05)$. 
Table 4. Effect of administration of honey, propolis, and STR on biochemical profiles of the urine on days 15. STR; Streptozotocin. * $\mathrm{P}<0.05$; compared to control. $+\mathrm{P}<0.05$; compared to STR. \&P $<0.05$; compared to STR+ honey. $\times \mathrm{P}<0.05$; compared to STR+ propolis

\begin{tabular}{|c|c|c|c|c|c|c|}
\hline Variables & Control & STR & Honey+ STR & Propolis + STR & Honey+ propolis + STR & $\mathrm{F} / \mathrm{P}$ value \\
\hline Glycose (g/l) & $0.82 \pm 0.14$ & $6.41 \pm 0.97 *$ & $4.44 \pm 0.51{ }^{*}+$ & $5.56 \pm 0.52 * \&$ & $1.87 \pm 0.33^{*}+\& x$ & $89.3 / 0.0000$ \\
\hline Creatinine $(\mathrm{mg} / \mathrm{l})$ & $680.4 \pm 64.72$ & $112.4 \pm 16.45^{*}$ & $300.2 \pm 67.25^{*}+$ & $178.2 \pm 41.3 * \&$ & $844 \pm 63.91^{*}+\& x$ & $179 / 0.0000$ \\
\hline Protein (g/l) & $0.20 \pm 0.02$ & $1.57 \pm 0.18^{*}$ & $0.76 \pm 0.14^{*}+$ & $0.83 \pm 0.24^{*}+$ & $0.34 \pm 0.02 *+\& x$ & $10.95 / 0.0001$ \\
\hline Microalbumin (mg/l) & $2.8 \pm 0.6$ & $20.53 \pm 3.91^{*}$ & $9.6 \pm 2.07^{*}+$ & $14.2 \pm 2.50 *+\&$ & $4.6 \pm 0.55^{*}+x$ & $47.49 / 0.0000$ \\
\hline Uric acid (mg/l) & $110.6 \pm 23.50$ & $44.5 \pm 10.31^{*}$ & $97 \pm 4.29 *_{+}$ & $59 \pm 6.04 * \&$ & $102 \pm 10.17+x$ & $27.05 / 0.0000$ \\
\hline Urea $(\mathrm{g} / \mathrm{l})$ & $45.2 \pm 3.09$ & $12.47 \pm 1.04^{*}$ & $30.76 \pm 13.05+$ & $14.40 \pm 1.53 * \&$ & $44.4 \pm 2.48+x$ & $32.47 / 0.0000$ \\
\hline Potassium (mmol/l) & $111 \pm 6.97$ & $202 \pm 15.02 *$ & $142.2 \pm 21.52^{*}+$ & $81.1 \pm 7.35 *+\&$ & $109.4 \pm 8.79+x$ & $63.24 / 0.0000$ \\
\hline Sodium $(\mathrm{mmol} / \mathrm{l})$ & $51.3 \pm 5.40$ & $43.6 \pm 5.32$ & $52 \pm 14.97$ & $46.5 \pm 2.96$ & $50.2 \pm 5.07$ & $1.276 / 0.312$ \\
\hline Chloride (mmol/l) & $98 \pm 9.35$ & $31.4 \pm 8.56^{*}$ & $97 \pm 12.06^{*}+$ & $32.6 \pm 8.32 * \&$ & $176.2 \pm 14.15^{*}+x$ & $160.4 / 0.0000$ \\
\hline Calcium (mg/l) & $156.6 \pm 9.04$ & $159.6 \pm 9.40$ & $151.4 \pm 10.04$ & $80 \pm 13^{*}+\&$ & $140.8 \pm 14.67 x$ & $42.85 / 0.000$ \\
\hline Phosphorous (mg/l) & $324 \pm 28.67$ & $94 \pm 7.65^{*}$ & $446.6 \pm 43.87^{*}+$ & $382 \pm 28.15^{*}+\&$ & $373 \pm 39.62+$ & $92.32 / 0.0000$ \\
\hline Magnesium (mg/l) & $143.95 \pm 5.32$ & $109.8 \pm 16.77^{*}$ & $129.5 \pm 7.83$ & $140.4 \pm 17.41+$ & $140.15 \pm 7.22+$ & 7.233/0.0009 \\
\hline
\end{tabular}

Table 5. Effect of honey, propolis, and STR on liver enzymes, lipids, and hemoglobin on day 15. STR; Streptozotocin. * $\mathrm{P}<0.05$; compared to control. $+\mathrm{P}<0.05$; compared to STR. $\& \mathrm{P}<0.05$; compared to STR+ honey. $\times \mathrm{P}<0.05$; compared to STR+ propolis

\begin{tabular}{|c|c|c|c|c|c|c|}
\hline Variables & Control & STR & Honey+STR & Propolis + STR & Honey+propolis + STR & $\mathrm{F} / \mathrm{P}$ values \\
\hline ALT (Ul/l) & $46 \pm 4.21$ & $71 \pm 1.58^{*}$ & $58.4 \pm 6.77+$ & $50 \pm 3.81+$ & $45 \pm 1.41+$ & $36.00 / 0.000$ \\
\hline AST (Ul/l) & $132.3 \pm 10.47$ & $159 \pm 10.63^{*}$ & $135.3 \pm 12.87$ & $149 \pm 8.51$ & $121.8 \pm 9.36+x$ & $91.92 / 0.000$ \\
\hline PAL (Ul/l) & $306.5 \pm 32$ & $967 \pm 28.25^{*}$ & $811.4 \pm 26.31^{*}$ & $863 \pm 23.71+$ & $421 \pm 15.29^{*}+\& x$ & $655.82 / 0.000$ \\
\hline Gama-GT (Ul/l) & $3.56 \pm 0.36$ & $4.5 \pm 0.79^{*}$ & $3.66 \pm 0.22$ & $4.34 \pm 0.7$ & $3.64 \pm 0.30$ & $3.55 / 0.023$ \\
\hline lactate dehydrogenase (Ul/l) & $422.3 \pm 66.98$ & $1431.5 \pm 47.96^{*}$ & $754 \pm 33.88^{*}+$ & $978.8 \pm 18.98^{*}+\&$ & $377.8 \pm 23.63+\& x$ & $551.6 / 0.000$ \\
\hline Creatinine kinase (Ul/l) & $1841 \pm 73.50$ & $4762 \pm 298.78^{*}$ & $3713 \pm 96.77^{*}$ & $2939 \pm 167.70^{*}+\&$ & $1788 \pm 51.49+\& x$ & $306.91 / 0.000$ \\
\hline Cholosterol (mg/dl) & $57 \pm 8$ & $68 \pm 2^{*}$ & $62 \pm 3$ & $66 \pm 3$ & $51 \pm 1+\& x$ & $11.69 / 0.000$ \\
\hline Triaglyceride (mg/dl) & $40 \pm 8$ & $55 \pm 1^{*}$ & $50 \pm 3$ & $55 \pm 13$ & $46 \pm 4$ & $3.92 / 0.164$ \\
\hline HDL (mg/dl) & $33 \pm 2$ & $22 \pm 2^{*}$ & $31 \pm 2+$ & $25 \pm 1 * \&$ & $35 \pm 2+x$ & $44.4 / 0.000$ \\
\hline Hemoglobin (g/dl) & $14.9 \pm 0.32$ & $11.6 \pm 0.30^{*}$ & $13.2 \pm 0.5+$ & $13 \pm 0.14+$ & $14.7 \pm 0.51+x \&$ & $63.5 / 0.000$ \\
\hline Hematocrit (\%) & $45.7 \pm 2.49$ & $38.05 \pm 1.04^{*}$ & $41.8 \pm 1.03$ & $40 \pm 0.7^{*}$ & $44.8 \pm 0.98+x$ & $27.7 / 0.000$ \\
\hline $\begin{array}{l}\text { White blood count } \\
\left(10^{*} 3 / \text { micro L }\right)\end{array}$ & $5.98 \pm 0.21$ & $5.01 \pm 0.62^{*}$ & $6.23 \pm 0.16+$ & $4.78 \pm 0.62 * \&$ & $4.95 \pm 0.70 * \&$ & $8.411 / 0.0004$ \\
\hline $\begin{array}{l}\text { Platelet count count } \\
\left(10^{*} 3 / \text { micro L }\right)\end{array}$ & $548 \pm 40.60$ & $531 \pm 45.35$ & $642.9 \pm 30.6^{*}+$ & $573 \pm 36.01$ & $547.2 \pm 30.72 \&$ & $7.105 / 0.001$ \\
\hline
\end{tabular}

\section{Histopathological studies}

There was congestion and hemorrhagic foci in kidney tissues collected from STR-treated rats, while mild congestion was noticed in the STR-treated group treated with honey (Fig. 4). The liver tissue examination showed vascular congestion, hepatocyte necrosis, hepatocyte binucleation, dilation of the centrilobular vein, and inflammatory portal areas in STR-treated rats (Fig. 5). However, with the use of honey and propolis, mild vascular congestion and hepatocyte necrosis were noticed. In the control group, examination of pancreatic tissue revealed many islets of Langerhans; however, it showed few of them in STR-treated rats (Fig. 6). Honey and propolis restored the markedly lowered number of islets of Langerhans in the STR-treated groups.

\section{Discussion}

The study showed protection of honey and propolis against acute STR direct effect and hyperglycemia on kidney and liver functions, lipid profile, hemoglobin, body weight, and proteinuria. It also showed protection of the interventions in the diabetic process via reducing hyperglycemia, decreasing HBA1c level, increasing insulin level, and ameliorating pancreatic damage. The changes in kidney and liver functions, dyslipidemia, and proteinuria are due to the acute effect of STR and hyperglycemia. The interventions alleviated crossly histological changes in the kidney, liver, and pancreas after the injection of STR and induction of hyperglycemia in rats. The results showed that the combination of honey and propolis was significantly more protective than honey or propolis individually. 
Fig. 4. Kidney specimens in various groups; Control (Control group), STR (STR-treated group), Honey (STR-treated+ honey group), Propolis (STR-treated +propolis group), and H-P (STR-treated+ honey and propolis group).

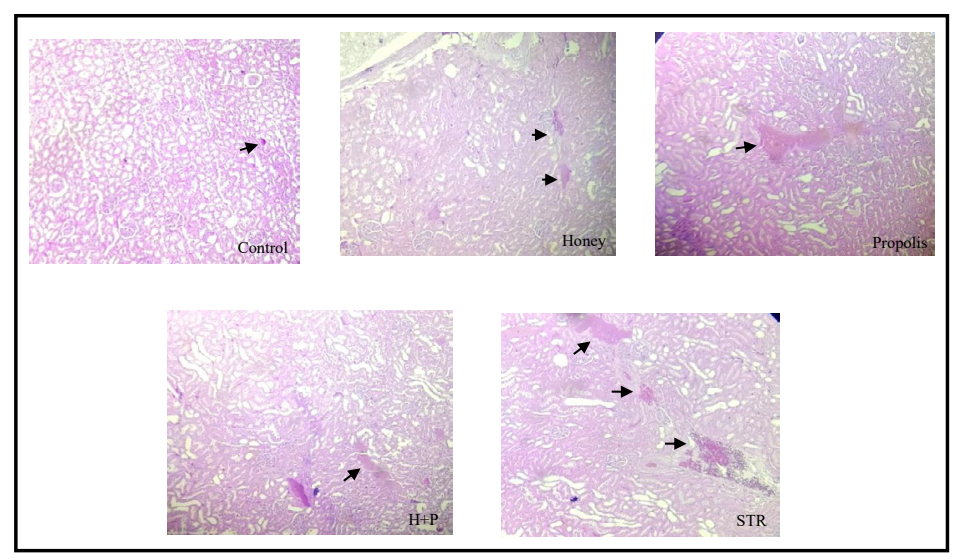

Fig. 5. Liver specimens in various groups; Control (Control group), STR (STR-treated group), Honey (STR-treated+ honey group), Propolis (STR-treated + propolis group), and H-P (STR-treated+ honey and propolis group).

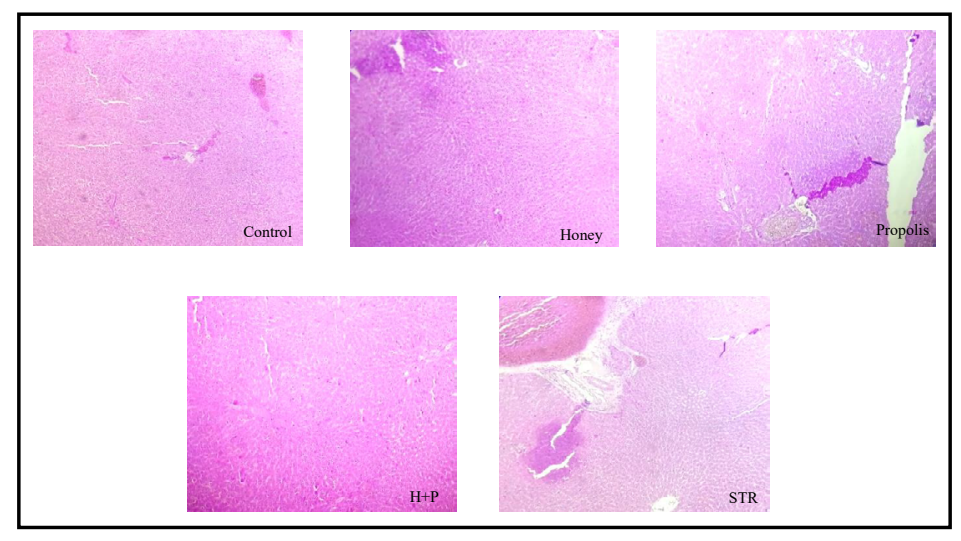

Fig. 6. Pancreas specimens in various groups; Control (Control group), STR (STR-treated group), Honey (STR-treated + honey group), Propolis (STR-treated + propolis group), and H-P (STRtreated + honey and propolis group).

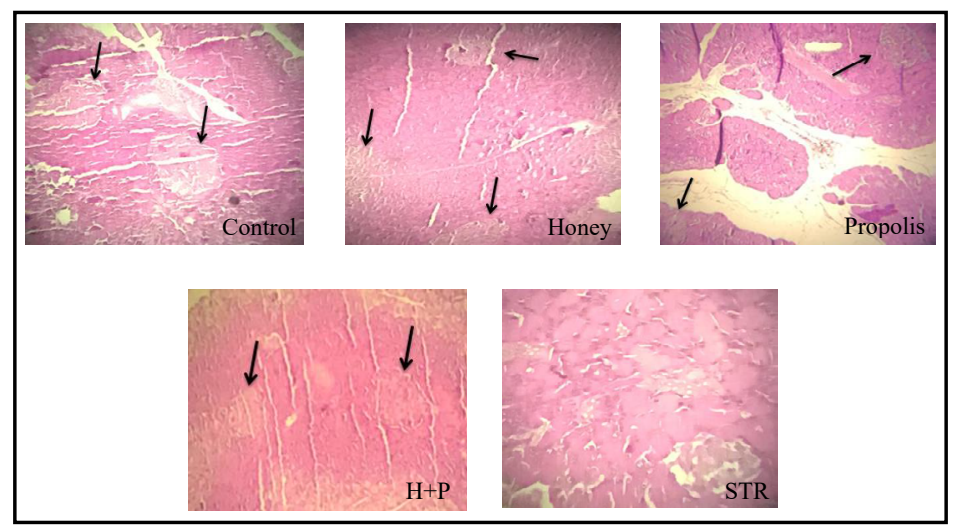

The chemical analysis revealed that honey and propolis contain abundant minerals, phenols, and flavonoids, exhibiting a strong antioxidant capacity. Propolis contains a higher amount of calcium, magnesium, sodium, phenols, and flavonoids and has a higher antioxidant capacity than honey. However, propolis contains significantly less quantity of potassium than honey. These compositions might explain, partly, the mechanism of action of honey and propolis.

The physicochemical characterization and the antioxidant content of honey samples vary with the harvest season, storage, nectar source, environmental conditions, and the beekeepers' intervention [41, 42]. The presented result showed that Arbutus unedo honey's analyzed parameters follow the International Honey Commission 2009 and codex standard for honey [43]. 
Arbutus unedo honey contains various kinds of phenols and flavonoids but has no caffeic and rosmoric acids. The total phenol content of 17 different Moroccan honey samples ranges from $16.38 \mathrm{mg} \mathrm{GAE} / 100 \mathrm{~g}$ (citrus honey) to $92.37 \mathrm{mg} \mathrm{GAE} / 100$ (thyme honey) [44]. Therefore, the phenolic content in Arbutus unedo honey (73.20 $\pm 2.74 \mathrm{GAE} / 100$-gram honey) is in the same range as Moroccan propolis. The content is higher than Manuka honey's phenolic content (71 mg GAE/100g) and less than Iranian honey phenolic content (193.8 $\mathrm{mg}$ GAE/100-gram hone) [45]. Interestingly, Arbutus unedo honey contains epicatechin (4.76+/$0.48 \mathrm{mg} / 100$-gram honey). Epicatechin is rarely found in honey samples. Our earlier study showed that thyme Vulgaris honey collected from Morocco has epicatechin with a higher concentration (6.91 $\pm 0.05 \mathrm{mg} / 100 \mathrm{gram}$ honey) than that found in Arbutus unedo honey [46].

Propolis contains different phenolic acids, and 18 compounds were identified using LC/DAD/ESI-MS ${ }^{n}$. All the compounds detected were phenolic acids and their ester derivatives. When standards were unavailable, the structural information was confirmed with UV data combined with MS fragmentation patterns (39). The analysis revealed that pinobanksin-3-Oacetate, pinocembrin, and caffeic acid phenylethyl ester were the most abundant phenolics found in the propolis sample. The phenolic profile found is almost similar to the poplar propolis type (39). The results of the free radical-scavenging, DPPH, and Ferric reducing power tests demonstrated that propolis showed a higher scavenging capacity against DPPH and Ferric reducing power than honey.

Administration of STR caused hyperglycemia with lowering of insulin level. It caused a considerable decrease in the islets of Langerhans. The administration of honey and propolis after induction of diabetes significantly restores high BGL and low insulin levels toward the normal range. It means that honey and propolis might have a role in the management of diabetes. STR significantly increased HOMA-IR and decreased QUIKI(*10-2). Therefore, STR increased BGL due to low insulin and by increasing insulin resistance and reducing insulin sensitivity. These changes were evident with the use of honey and propolis because of rising insulin levels.

Pancreatic tissue examination showed a low number of islets of Langerhans 15 days after induction of hyperglycemia and STR injection. However, honey and propolis administration ameliorated the destructive effect of STR on the pancreas, which was evident by a high number of islets of Langerhans. Also, this favorable effect might be due to the fastening of the healing process by honey and propolis.

HbA1c is a well-known parameter for evaluating diabetic control and hyperglycemia in diabetic patients and is used to diagnose diabetes. HbA1c is a marker for insulin resistance and endothelial dysfunction [47]. A significant elevation of HbA1c was obtained 15 days after induction of hyperglycemia and STR injection. Testing of HBA1c after an extended period might positively impact using honey and propolis to ameliorate the elevation of $\mathrm{HbA1c}$ in diabetes. It was found that honey reduces hyperglycemia and insulin resistance in diabetic patients [48]. Antioxidant alleviates oxidative stress in $\beta$-cells in the pancreas and stimulates insulin secretion [49]. Fructose and antioxidant content might be responsible for the honey hypoglycemic effect [50]. Although the management period with propolis and honey was two weeks, the HBA1c level was significantly lower in the honey and propolis treated diabetic groups compared to diabetic untreated groups.

The most important complications of diabetes are proteinuria and CKD. It was found that serum creatinine increases 12 weeks after STR administration and induction of hyperglycemia [51]. However, BU increased after one week indicating AKI without chronic glomerular endothelial cell injury [52]. Acute hyperglycemia could cause AKI and tubular injury and leads to oxidative stress [53]. The data presented showed that severe hyperglycemia was obtained two days after STR administration, which might play a role in inducing AKI, proteinuria, and a considerable decrease in the urinary excretion of creatinine, $\mathrm{BU}$, uric acid, phosphorous, and magnesium. AKI was evident by a significant elevation of the serum creatinine and BU after injection of STR. The treatment with honey or propolis significantly restored the abnormal kidney function and proteinuria toward the normal range; 
the combination of honey and propolis showed a better protective effect. A recent study showed that STR causes alpha 2u-globulin nephropathy in $>80 \%$ of the moribund Wister male rats to manifest diabetic kidney injury within two weeks after STR injection [54]. It was found that hyperglycemia contributes to direct kidney damage, particularly in renal tubular cells [55]. Examination of renal tissue showed congestion and bleeding areas, which were less evident with honey or propolis. In an earlier study, we have found that propolis reduces urinary protein excretion and crystalluria and improves AKI and acute liver injury caused by ethylene glycol ingestion in rats [20]. Propolis contains a large quantity of flavonoids, and it has higher antioxidant activity than honey, as confirmed by the present result [12]. It was found that phenols and flavonoids improve AKI, renal fibrosis, and inflammation [56, 57]. These findings might partly explain honey and propolis protective effect mechanism against STR and hyperglycemia-induced AKI and proteinuria. Further studies are currently in progress in our laboratory to explore in-depth the mechanism of action.

STR injection causes lower hemoglobin and hematocrit after 15 days, restored to normal range using propolis or honey. It was found that hyperglycemia as a manifestation of type 1 diabetes reduced red blood cell count, hemoglobin concentration, and hematocrit level [58]. Hyperglycemia increases the production of reactive oxygen species, which impaires the erythrocyte membrane [59]. The beneficial effect of honey and propolis might be related to antioxidant activity and their minerals content. Measurement of erythropoietin, iron, vitamin B12, and folate is essential to further understand the mechanism of action.

STR injection and the induction of hyperglycemia in rats causes liver toxicity and elevation of liver enzymes level [59]. In the present study, STR causes acute liver injury, which was evident by the elevation of liver enzymes and histological changes seen in the liver tissue after 15 days. These changes were restored toward the normal range after treatment with honey or propolis, which might be due to the hepatoprotective effect of propolis and honey. It was found that hyperglycemia reduces antioxidants, increases levels of malondialdehyde, and leads to oxidation-mediated liver damage [60]. Honey and propolis might prevent liver injury by their hypoglycemic and antioxidant activity, which need further testing,

STR and hyperglycemia elevated cholesterol, triglyceride, lactate dehydrogenase, and decreased HDL. These changes considerably were restored by honey and propolis. Honey reduces cholesterol levels because of its antioxidant content [61].

The data showed that honey and propolis contain a high quantity of antioxidants and increased antioxidant capacity; propolis has a higher antioxidant amount and activity than honey. Propolis contains a higher level of minerals than honey except for potassium level, which was higher in the honey sample. In STR-treated rats, there was a significant elevation in BGL, HBA1c, serum creatinine, BU, liver enzymes, total cholesterol, TG, LDH, HOMA-IR, and urine excretion of protein, albumin, and glucose. A significant lowering in insulin level, QUIKI (*10-2), body weight, hemoglobin, HDL, and urine excretion of creatinine, urea, uric acid, phosphorous, and magnesium. Histopathological examination showed pathological changes in the liver, pancreas, and kidney tissues. These changes were significantly alleviated by honey, propolis, and a combination of honey and propolis; the combination was more effective than honey or propolis individually. Honey, propolis, and their combination are preventive against histopathological changes noted in STR-treated rats. The mechanism of action is unknown, but it might be related to propolis and honey's antioxidant and hypoglycemic activity. It was found that honey, mixed honey, propolis, or mixed propolis, or their combination showed a therapeutic activity in diabetic nephropathy established six weeks after administration of STR in rats by ameliorating kidney failure, hepatic injury, proteinuria and microalbuminuira (Al-Waili, unpublished). The author suggested that honey and propolis might represent a safe and valuable natural therapeutic intervention in managing proteinuria, CKD, and diabetic complications.

The main limitation is the short period of study (15 days). This period reflects the acute effect of STR and hyperglycemia. The study aimed to evaluate the protective effect of honey and propolis and their combination in STR-treated rats, AKI, hepatic injury, proteinuria, and dyslipidemia. The administration of honey or propolis should be started 6-8 weeks after 


\section{Cellular Physiology Cell Physiol Biochem 2022;56:66-81

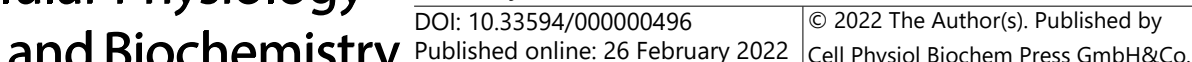 \\ Touzani et al.: Honey, Propolis, Acute Kidney Injury and Liver Injury}

induction of diabetic state to study the therapeutic effect of the interventions in STR induced type 1 diabetic. Therefore, a more extended period will give a better view of the therapeutic effect of the interventions on chronic changes caused by STR and diabetic complications.

\section{Conclusion}

Honey and propolis have a protective effect in AKI and liver injury induced by STR and diabetic state. The combination of honey and propolis has better protection than honey or propolis. Honey and propolis prevent proteinuria. This finding is significant and a step forward to prevent or treat proteinuria in CKD and diabetes. Honey and propolis can alleviate type 1 diabetes state that was evident by improving BGL, insulin level, and HBA1c toward normal level and alleviating the pancreatic damage caused by STR. The combination of honey and propolis resulted in better protection, which was evident by statistical analysis compared to the control group, honey treated group, and propolis treated group. Interestingly, honey and propolis are natural ingredients and safe. Therefore, they represent a suitable intervention to be tested in a clinical trial. Further studies to explore the mechanism of action are currently in progress in our laboratories.

\section{Acknowledgements}

\section{Author Contributions}

S. Touzani and B. Lyoussi: Designed the experimental protocols and participated in the experimental work and writing part of the paper; N. Al-Waili: Data collection, Analysis of data, writing the paper, submission for publication; H. Imtara: Designed the experimental protocols and participated in the experimental work; A. Aboulghazi: Biochemical analysis; N. Hammas: Histopathology study; S. Falcao and M. Vilas-Boas: Phytochemical HPLC; I. El Arabi: Participated in the experimental work; W. Al-Waili: Data collection, statistical analysis.

New York Medical Care for Nephrology, New York, paid a part of the publication fee.

\section{Statement of Ethics}

Ethics approval was obtained from Sidi Mohamed Ben Abdallah University Mohammed, Fez, the Animal Facility and the Laboratory of Physiology-Pharmacology \& Environmental Health at the Faculty of Science Dhar Mahraz of Fez, Morocco (USMBA-PPSE 2017-04). All efforts were made to minimize animal suffering and the number of animals used.

\section{Disclosure Statement}

The authors declare that no conflicts of interest exist.

\section{References}

1 Al-Waili N, Al-Waili H, Al-Waili T, Salom K: Natural antioxidants in the treatment and prevention of diabetic nephropathy; a potential approach that warrants clinical trials. Redox Rep 2017;22:99-118.

2 Erejuwa O, Sulaiman A, Wahab S, Sirajudeen N, Salleh S, Gurtu S: Differential responses to blood pressure and oxidative stress in streptozotocin-induced diabetic Wistar-Kyoto rats and spontaneously hypertensive rats: effects of antioxidant (honey) treatment. Int J Mol Sci 2011;12:1888-1907.

3 Erejuwa O, Sulaiman A, Wahab S, Sirajudeem S, Salleh S, Gurtu S: Antioxidant protective effect of glibenclamide and metformin in combination with honey in pancreas of streptozotocin induced diabetic rats. Inter J Mol Sci 2010;11:2056-2066. 


\section{Cellular Physiology Cell Physiol Biochem 2022;56:66-81 \begin{tabular}{l|l|l} 
and Biol: 10.33594/000000496 & C 222 The Author(s). Published by
\end{tabular} and BiOChemistry Published online: 26 February 2022 Cell Physiol Biochem Press GmbH\&Co. KG \\ Touzani et al.: Honey, Propolis, Acute Kidney Injury and Liver Injury}

4 Bahrami M, Ataie-Jafari A, Hosseini S, Foruzanfar H, Rahmani M, Pajouhi M: Effects of natural honey consumption in diabetic patients: an 8-week randomized clinical trial. Intern J Food Sci Nutr 2009;60:618626.

5 Al-Waili N: Intrapulmonary administration of natural honey solution, hyperosmolar dextrose or hypoosmolar distill water to normal individuals and to patients with type 2 diabetes mellitus or hypertension: their effects on blood glucose level, plasma insulin and C-peptide, blood pressure and peaked expiratory flow rate. Eur J Med Res 2003;8:295-303.

6 Ding Y, Xu M, Lu Q Wei P, Tan J, Liu R: Combination of honey with metformin enhances glucose metabolism and ameliorates hepatic and nephritic dysfunction in STZ-induced diabetic mice. Food Funt 2019;10:75767587.

7 Abdul Aziz M, Giribabu N, Rao P, Salleh N: Pancreatoprotective effects of Geniotrigona thoracica stingless bee honey in streptozotocin-nicotinamide-induced male diabetic rats. Biomed Pharmacother 2017;89:135145.

8 Al-Waili NS: Effects of honey on the urinary total nitrite and prostaglandins concentration. Int Urol Nephrol 2005;37:107-111.

9 Al-Waili NS: Intravenous and intrapulmonary administration of honey solution to healthy sheep: effects on blood sugar, renal and liver function tests, bone marrow function, lipid profile, and carbon tetrachlorideinduced liver injury. J Med Food 2003;6:231-247.

10 Al-Waili NS, Saloom KY, Akmal M, Al-Waili F, Al-Waili TN, Al-Waili AN, Ali A: Honey ameliorates influence of hemorrhage and food restriction on renal and hepatic functions, and hematological and biochemical variables. Int J Food Sci Nutr 2006;57:353-362.

11 Al-Waili NS, Saloom KY, Al-Waili TN, Al-Waili AN, Akmal M, Al-Waili FS, Al-Waili HN: Influence of various diet regimens on deterioration of hepatic function and hematological parameters following carbon tetrachloride: a potential protective role of natural honey. Nat Prod Res 2006;20:1258-1264.

12 El-Guendouz S, Al-Waili N, Aazza S, Elamine Y, Zizi S, Al-Waili T: Antioxidant and diuretic activity of coadministration of Capparis spinosa honey and propolis in comparison to furosemide. Asian Pac J Trop Med 2017;10:974-980.

13 Erejuwa O, Gurtu S, Sulaiman S, Wahab M, Sirajudeen K, Salleh M: Hypoglycemic and antioxidant effects of honey supplementation in streptozotocin-induced diabetic rats. Int J Vitam Nutr Res 2010;80:74-82.

14 Al Ghamdi A, Badr G, Hozzein WN, Allam A, Al-Waili NS, Al-Wadaan MA: Oral supplementation of diabetic mice with propolis restores the proliferation capacity and chemotaxis of $\mathrm{B}$ and $\mathrm{T}$ lymphocytes towards CCL21 and CXCL12 by modulating the lipid profile, the pro-inflammatory cytokine levels and oxidative stress. BMC Immunol 2015;16:54.

15 Al-Waili N, Al-Ghamdi A, Ansari MJ: Synergistic effects of honey and propolis toward drug multi-resistant Staphylococcus aureus, Escherichia coli and Candida albicans isolates in single and polymicrobial cultures. Int J Med Sci 2012;9:793-800.

16 Al-Hariri M, Eldin T, Abu-Hozaifa B, Elnour A: Glycemic control and anti-osteopathic effect of propolis in diabetic rats. Diabetes Metab Syndr Obes 2011;4:377-384.

17 Li Y, Chen M, Xuan H, Hu F: Effects of encapsulated propolis on blood glycemic control, lipid metabolism, and insulin resistance in type 2 diabetes mellitus rats. Evid Based Compl Alt Med 2012;2012:981896.

18 El Rabey HA, Al-Seeni MN, Bakhashwain AS: The antidiabetic activity of Nigella sativa and propolis on streptozotocin-induced diabetes and diabetic nephropathy in male rats. Evid Based Complement Alternat Med 2017;2017:5439645.

19 Boisard S, Le Ray AM, Gatto J, Aumond MC, Blanchard P: Chemical composition, antioxidant and anti-AGEs activities of a French poplar type propolis. J Agric Food Chem 2014;62:1344-1351.

20 El Menyiy N, Al Waili N, Bakour M, Al-Waili H, Lyoussi B: Protective effect of propolis in proteinuria, crystaluria, nephrotoxicity and hepatotoxicity induced by ethylene glycol ingestion. Arch Med Res 2016;47:526-533.

21 Silici S, Kutluca S: Chemical composition and antibacterial activity of propolis collected by three different races of honeybees in the same region. J Ethnopharmacol 2005;99:69-73.

22 Huang S, Zhang C, Wang K, Li G,Hu F: Recent advances in the chemical composition of propolis. Molecules 2014;19:19610-19632.

23 Yamamoto H, Uchigata Y, Okamoto H: DNA strand breaks in pancreatic islets by in vivo administration of alloxan or streptozotocin. Biochem Biophys Res Commun 1981;103:1014-1020. 


\section{Cellular Physiology Cell Physiol Biochem 2022;56:66-81 \begin{tabular}{l|l|l} 
and Biol: 10.33594/000000496 & 2022 The Author(s). Published by
\end{tabular} and BiOChemistry Published online: 26 February 2022 Cell Physiol Biochem Press GmbH\&Co. KG \\ Touzani et al:: Honey, Propolis, Acute Kidney Injury and Liver Injury}

24 Okamoto H, Takasawa S: Okamoto model for necrosis and its expansions, CD38-cyclic ADP-ribose signal system for intracellular Ca2+ mobilization and Reg (Regenerating gene protein)-Reg receptor system for cell regeneration. Proc Jpn Acad Ser B Phys Biol Sci 2021;97:423-461.

25 Leiter H: Multiple low-dose streptozotocin-induced hyperglycemia and insulitis in C57BL mice: influence of inbred background, sex, and thymus. Proc Natl Acad Sci U S A 1982;79:630-634.

26 Gajdosík A, Gajdosíková A, Stefek M, Navarová J, Hozová R: Streptozotocin-induced experimental diabetes in male Wistar rats. Gen Physiol Biophy 1999;18:54-62.

27 Rodrigues B, Cam M, Kong J, Goyal R, McNeill J: Strain differences in susceptibility to streptozotocininduced diabetes: effects on hypertriglyceridemia and cardiomyopathy. Cardiovascul Res 1997;34:199-205.

28 Furman L: Streptozotocin-induced diabetic models in mice and rats. Current Protocols 2021; DOI: 10.1002/ cpz1.78.

29 Bogdanov S: Harmonised methods of the international IHC. Bee Product Sci 2009;5:1-62.

30 Naab A, Tamame A, Caccavari A: Palynological and physicochemical characteristics of three unifloral honey types from central Argentina. Spanish J Agricult Res 2008;6:566-576.

31 Brudzynski K, Miotto D: Honey melanoidins: Analysis of the compositions of the high molecular weight melanoidins exhibiting radical-scavenging activity. Food Chemist 2011;127:1023-1030.

32 Silva R, Videira R, Monteiro P, Valentão P, Andrade B: Honey from Luso region (Portugal): Physicochemical characteristics and mineral contents. Microchemical J 2009;93:73-77.

33 Singleton L, Rossi Jr A: Colorimetry of total phenolics with phosphomolybdic-phosphotungstic acid reagents. Am J Enol Vitic 1965;16:144-158.

34 Miguel G, Nunes S, Dandlen A, Cavaco M, Antunes D: Phenols, flavonoids and antioxidant activity of aqueous and methanolic extracts of propolis (Apis mellifera L.) from Algarve, South Portugal. Food Sci Technol 2014:34:16-23.

35 Aljadi A, Yusoff K: Isolation and identification of phenolic acids in Malaysian honey with antibacterial properties. Turkish J Med Sci 2003;33:229-236.

36 Prieto P, Pineda M, Aguilar M: Spectrophotometric quantitation of antioxidant capacity through the formation of a phosphomolybdinum complex: Specific application to the determination of Vitamin E. Analyt Bioch 1999;269:337-341.

37 Brand-Williams W, Cuvelier M, Berset C: Use of a free radical method to evaluate antioxidant activity. LWT Food Sci Technol 1995;28:25-30.

38 Oyaizu M: Studies on products of browning reaction. Antioxidative activities of products of browning reaction prepared from glucosamine. The Japanese Journal of Nutrition and Dietetics 1986;44:307-315.

39 Falcão I, Vale N, Gomes P, Domingues M, Freire C, Cardoso M, Vilas-Boas M: Phenolic profiling of Portuguese propolis by LC-MS spectrometry: uncommon propolis rich with flavonoid glycosides. Phytochem Anal 2013;24:309-318.

40 Falcão I, Tomás A, Vale N, Gomes P, Freire C, Vilas-Boas M: Phenolic quantification and botanical origin of Portuguese propolis. Ind Crops Prod 2013;49:805-812.

41 Chen H, Sullivan G, Quon M: Assessing the predictive accuracy of QUICKI as a surrogate Index for insulin sensitivity using a calibration model. Diabetes 2005;54:1914-1925.

42 Saxena S, Gautam S, Sharma A: Physical, biochemical and antioxidant properties of some Indian honeys. Food Chemist 2010;118:391-397.

43 Food and Agriculture Organization of the United Nations; World Health Organization: Codex Alimentarius. Standard for honey. CXS12-1981, 1981. Revised in 1987, 2001. Amended in 2019.

44 Aazza S, Lyoussi B, Antunes D, Miguel MG: Physicochemical characterization and antioxidant activity of 17 commercial Moroccan honeys. Int J Food Sci Nutr 2014;65:449-457.

45 Stagos D, Soulitsiotis N, Tsadila C, Papaeconomou S, Arvanitis C, Ntontos A, Karkanta F, Adamou-Androulaki S, Petrotos K, Spandidos DA, Kouretas D, Mossialos D: Antibacterial and antioxidant activity of different types of honey derived from Mount Olympus in Greece. Int J Mol Med 2018;42:726-734.

46 Imtara H, Al-Waili N, Aboulghazi A, Abdellaoui A, Al-Waili T, Lyoussi B: Chemical composition and antioxidant content of Thymus vulgaris honey and Origanum vulgare essential oil; their effect on carbon tetrachloride-induced toxicity. Vet World 2012;14:292-301.

47 Sato H, Carvalho G, Sato T, Lattermann R, Matsukawa T, Schricker T: The association of preoperative glycemic control, intraoperative insulin sensitivity, and outcomes after cardiac surgery. J Clin Endocrinol Metab 2010;95:4338-4344. 


\section{Cellular Physiology Cell Physiol Biochem 2022;56:66-81

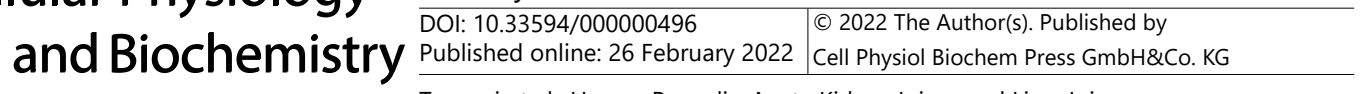 \\ Touzani et al.: Honey, Propolis, Acute Kidney Injury and Liver Injury}

48 Abdulrhman M, El-Hefnawy M, Hussein R, El-Goud AA: The glycemic and peak incremental indices of honey, sucrose and glucose in patients with type 1 diabetes mellitus: effects on C-peptide level-a pilot study. Acta Diabetol 2011;48:89-94.

49 Batumalaie K, Qvist R, Yusof K, Ismail I, Sekaran S: The antioxidant effect of the Malaysian Gelam honey on pancreatic hamster cells cultured under hyperglycemic conditions. Clin Exp Med 2014;14:185-195.

50 Erejuwa 00, Sulaiman SA, Wahab MS: Honey-a novel antidiabetic agent. Int J Biol Sci 2012;8:913-934.

51 Wang W, Li Z, Chen Y, Wu H, Zhang S, Chen X: Prediction value of serum NGAL in the diagnosis and prognosis of experimental acute and chronic kidney injuries. Biomolecules 2020 30;10:98.

52 Tesch H, Allen J:Rodent models of streptozotocin-induced diabetic nephropathy. Nephrol Carlton 2007;12:261-266.

53 Wang J, Yue X, Meng C, Wang Z, Jin X: Acute hyperglycemia may induce renal tubular injury through mitophagy inhibition. Front Endocrinol (Lausanne) 2020;11:536213.

54 Kengkoom K, Angkhasirisap W, Kanjanapruthipong T, Tungtrakanpoung R, Tuentam K, Phansom N, Ampawong S: Streptozotocin induces alpha-2u globulin nephropathy in male rats during diabetic kidney disease. BMC Vet Res 2021;17:105.

55 Flemming NB, Gallo LA, Forbes JM: Mitochondrial dysfunction and signaling in diabetic kidney disease: oxidative stress and beyond. Semin Nephrol 2018;38:101-110.

56 Meng M, Li D, Wu WF, Tang PMK, Ren GL, Gao L, Li XF, Yang Y, Xu T, Ma TT, Li Z, Huang C, Zhang L, Lv XW, Li J: Wogonin protects against cisplatin-induced acute kidney injury by targeting RIPK1-mediated necroptosis. Lab Invest 2018;98:79-94.

57 Wu Y, Quan Q, Cao Q Lin Y, Yue C, Bi R, Cui X: Quercetin alleviates acute kidney injury by inhibiting ferroptosis. J Adv Res 2020;28:231-243.

58 Juhi A, Pradnya S, Priyadarshini H, Latha A, Samatha, Ratnam M: Comparative study of erythrocyte fragility in diabetes mellitus and non diabetes mellitus. Inter J Med Res Health Sci 2015;4:183-188.

59 Jain K: Hyperglycemia can cause membrane lipid peroxidation and osmotic fragility in human red blood cells. J Biol Chem 1989;264:21340-21345.

60 Behrouj H, Ziamajidi N, Abbasalipourkabir R, Goodarzi MT, Saidijam M: Hypoglycemic and antioxidant effects of oral administration of garlic extract in the livers of type 1 diabetic rats. J Basic Clin Physiol Pharmacol 2018;24;30:245-250.

61 Ramli NZ, Chin KY, Zarkasi KA, Ahmad F: A Review on the protective effects of honey against metabolic syndrome. Nutrients 2018;10:1009. 